\title{
Max Scheler: educar é humanizar
}

\author{
Max Scheler: to educate is to humanize
}

Almiro Schulz*

\section{Resumo}

A educação foi e é objeto de estudo, de análise, de reflexão e de interesse de agentes de múltiplos setores e áreas de saberes, seja no âmbito das políticas públicas, da economia, seja no acadêmico, em especial, das áreas de sociologia, história, psicologia e filosofia. Este artigo tem por objetivo apresentar um aspecto central da visão da filosofia da educação de Max Scheler, segundo o qual educar significa humanizar. O texto é resultado de um projeto de pesquisa sobre Max Scheler, com base em uma revisão bibliográfica de textos primários e de comentadores. Mesmo que Scheler não tivesse a educação como problema originário de seus estudos e pesquisas, pois é mais conhecido por suas preocupações e elaborações no campo da ética, em especial sobre os valores, ele desenvolveu um sistema axiológico; tratou da filosofia da religião; e, posteriormente, voltou-se para a antropologia filosófica. Essas questões acabaram gerando a necessidade de inserir em suas abordagens e discussões a educação como processo de humanização, que é uma de suas concepções-chave na visão educativa. Parte, portanto, de uma antropologia, tendo como ponto central a indagação: quem é o homem? Humanizar significa desenvolver o espírito, o que é peculiar ao homem e distingue-o dos outros seres vivos. É um processo, um vir a ser, um ir e vir, um avançar e retroceder. Educar é humanizar.

Palavras-chave: Educação. Filosofia. Humanização. Max Scheler.

\section{Abstract}

Education has been the object of study, of analysis, of reflection, and of interest to agents of multiple sectors and areas of knowledge, whether in the sphere of public policy and economics or among scholars, especially in the areas of sociology, history, psychology, and philosophy. The aim of this text is to present a central aspect of the view of philosophy of education of Max Scheler, according to whom to educate means to humanize. This text is the result of a research project on Max Scheler based on a bibliographical review of primary texts and of commentators. Scheler did not have education as the fundamental issue of his studies and research; he is better known for his concerns and work in the field of ethics, especially in regard to values. He developed an axiological system, directed himself to philosophy of religion, and later returned to philosophical anthropology. These questions ended up generating the need to insert education in his approaches and discussions as a process of humanization, which is one of the key conceptions in his educational perspective. It is therefore based on an anthropology with the core question: who is the human person? To humanize means to develop the spirit, which is particular to humans and distinguishes them from other living beings. It is a process, a becoming, a back and forth movement, an advance and withdrawal. To educate is to humanize.

Keywords: Education. Humanization. Max Scheler. Philosophy.

Recebido em: 12/01/2017 - Aprovado em: 04/07/2017

http://dx.doi.org/10.5335/rep.v24i3.7765

Doutor em Educação pela Universidade Metodista de Piracicaba (1999). Professor efetivo, adjunto IV, da Universidade Federal de Goiás. E-mail: almiroschulz@yahoo.com.br 
A educação foi e é objeto de estudo, de análise, de reflexão e de interesse de agentes de múltiplos setores e áreas de saberes, seja no âmbito das políticas públicas, da economia, seja no âmbito acadêmico, em especial das áreas de sociologia, história, psicologia e filosofia. O texto tem por objetivo apresentar um aspecto central da visão da filosofia de educação de Max Scheler, segundo o qual educar significa humanizar, além de contribuir para o campo da filosofia da educação. $O$ texto é resultado de um projeto de pesquisa sobre Max Scheler, de estudos e de revisão bibliográfica de textos primários e de comentadores. Mesmo que não haja nenhum texto do autor especificamente voltado para a educação, os mais específicos nessa área são uma conferência publicada sob o título Büldung und Wissen (1947) e um texto sobre o ensino superior, Universidad y Universidad popular (1959). No entanto, a questão da educação e sua visão sobre ela podem ser apreendidas em outros textos, dentre eles: Modelos e líderes (1998), Visão filosófica do mundo (1986), na palestra "O homem na era da conciliação", proferida em 1927, e em outra apresentada em 1918, "Da reconstrução cultural da Alemanha", traduzida e publicada no livro Do eterno do homem (2015). Também foram consultados textos de comentadores, tais como: Amor x conhecimento: inter-relação ético-conceitual em Max Scheler (MEISTER, 1994), Antropologia filosófica e educação: perspectivas a partir de Max Scheler (SCHAEFER, 1995) e algumas dissertações de mestrado.

Mesmo que Scheler não tenha a educação como problema originário de estudos e pesquisas, pois é mais conhecido pelas suas preocupações e elaborações no campo da ética, em especial sobre os valores, desenvolveu um sistema axiológico, tratou da filosofia da religião e, também, voltou-se para a questão antropológica, desenvolvendo uma antropologia filosófica. No entanto, essas questões principais - ética, religião e antropologia - acabaram envolvendo-o com outras questões, ou seja, fizeram com que ele inserisse em suas abordagens e discussões outros problemas, dentre eles a educação, principalmente porque viveu a fase em que a educação era objeto de preocupação e de divergência entre diferentes segmentos, sobretudo entre os anos 1920 e 1930, conforme apresenta Fritz K. Ringer em $O$ declínio dos mandarins alemães (2000). Pode-se, assim, considerar que a educação também foi um de seus problemas de análise e discussão, sendo, como processo de humanização, uma de suas concepções-chave na visão educativa. Parte-se, portanto, de uma antropologia, tendo como ponto central a indagação: quem é o homem? Humanizar significa desenvolver o espírito, o que é peculiar ao homem, e é isso que o distingue dos outros seres vivos. É um processo, um vir a ser, um ir e vir, um avançar e um retroceder segundo a hierarquia na valoração, que é a forma de percepção que o homem e a sociedade têm dos valores e vivenciam no seu cotidiano. 


\section{Crítica à realidade educacional de seu tempo}

Scheler viveu, em seus poucos anos, num contexto bastante crítico: o antes, o durante e o pós-Primeira Guerra Mundial. Tomou como parâmetro o ideal do Iluminismo, em especial o firmado em Kant e Hegel. O primeiro focado no processo do esclarecimento; o segundo, no espírito. Apoiou-se, ainda, no otimismo positivista centrado na confiança da ciência. A culminância da guerra e os seus efeitos, sobretudo na civilização europeia, em especial, na alemã, foram como uma evidência de um descaminho histórico. $\mathrm{O}$ que o levou a buscar compreender o contexto que chegou a chamar de decadência em razão da inversão de valores, segundo sua concepção, da escala hierárquica. Em conferência proferida em 17 de janeiro de 1925, sob o tema: "As formas do saber e a cultura" (1986), Scheler tece uma longa crítica sobre a educação na Alemanha. Nesse sentido, Ringer destaca:

Scheler finalmente zombava da "profissionalização unilateral" de seus contemporâneos e de uma especialização "que renunciou sistematicamente a qualquer concordância em termos de objetivos por serem coisas distintas de todas as questões de técnica”. Achava que o ensino superior alemão já não produzia "homens de inteligência [geistige Personen], que influenciam a totalidade da vida da nação como modelos e líderes". A universidade, dizia ele, degenerara numa escola profissionalizante (2000, p. 243, grifos do autor).

Assim, dois aspectos de sua crítica, relativos à educação, podem ser destacados, sendo descritos a seguir.

A civilização ocidental necessita de uma atitude nova.

A civilização ocidental, com o passar do tempo, afastou-se do que considerou ser mais elevado para o homem e para a humanidade, dando primazia ao saber utilitário e à ciência positiva. Isso não era apenas a visão de Scheler na Alemanha. Segundo Ringer (2000), entre os anos de 1870 e 1930, é possível identificar três segmentos entre os acadêmicos: os ortodoxos, os moderados e os modernistas. Estes se posicionavam com maior ou menor aversão às mudanças em curso: o positivismo, o utilitarismo, a ascensão da população de empresários e o alcance da população mais baixa ao nível de educação superior. Tudo isso era visto como ameaça à educação culta, porque visava a uma educação voltada para a técnica e a prática.

Para Scheler, essa atitude nova precisava emergir da elite acadêmica, principalmente das universidades: "Nunca, em nenhum tempo da história por mim conhecido, a genuína cultura foi para as elites dirigentes mais necessária e mais difícil" (SCHELER, 1986, p. 20). Ringer observa que: 
[...] as universidades haviam cumprido apenas uma parte de suas funções [...] haviam negligenciado seu dever de tornar o conhecimento e as tradições culturais acessíveis a todas as classes da população; tinham-se transformado muito mais em especialistas e técnicos do que em seres humanos plenamente desenvolvidos; os professores não haviam sido modelos pessoais para seus alunos (2000, p. 263).

Mesmo considerando que as mudanças se processam, no decorrer do tempo, sempre por uma elite de pessoas, nela e por meio dela se dá a formação estrutural como ponto de partida. No entanto, a educação desenvolvida por meio das instituições não deve negligenciar a formação cultural a ser dada às multidões e às massas de nível cultural diferente da elite. Isso é o que Scheler propunha por meio da universidade popular, que não teria o objetivo de uma mera especialização técnica, mas que visaria, também, a uma formação humanista.

\section{É preciso recuperar a dimensão do saber que caiu em esquecimento.}

Scheler, em uma de suas conferências publicadas em 1928, classifica o saber em três formas ou espécies: o saber de dominação ou de realização, o saber da essência ou cultural e o saber metafísico ou de salvação (SCHELER, 1986, p. 07-19). Essa classificação está inserida no contexto dos grandes debates e embates em torno dos descaminhos e caminhos que a sociedade alemã viveu após a Primeira Guerra Mundial (1914-1917), a revolução de 1918 a 1919 e a busca de uma reconfiguração social. Em suas críticas, o filósofo não aponta apenas possíveis fatores da decadência cultural, mas também indica possíveis saídas para recuperação, assim como outros acadêmicos, principalmente os da ala idealista ortodoxa, que atribuíam a causa ao espírito, apostando nele como caminho da restauração. Scheler entendia que havia um equívoco de análise da parte de alguns teóricos ou acadêmicos, fosse do lado dos radicais ortodoxos, fosse dos liberais modernistas, por não compreenderem os níveis ou espécies do saber, quando, então, analisa e argumenta sobre a realidade cultural à luz dessa classificação de saberes.

O saber de dominação ou realização, primeira espécie do saber, está no nível da realização técnica, que não deixa de ter sua relevância para a sociedade, mas não pode se tornar a que ocupa um lugar exclusivo, já que esse nível de saber degenera a cultura, o humano (SCHELER, 1986, p. 10). É preciso enfrentar e superar essa tendência presente na sociedade alemã. O saber da essência, segundo nível ou espécie do saber (SCHELER, 1986, p. 11), é o saber da cultura, é a forma ou a espécie em que ele enquadra a educação, é aí que está o caminho da reconstrução, caminho que defende não uma formação meramente técnica, utilitarista, mas a humanização, a formação do ser, que é o destino próprio do homem. O terceiro nível ou espécie do saber, que é o da salvação ou metafísico (SCHELER, 1986, p. 15), é 
o saber na hierarquia mais alta, que é de fato o tornar-se microcosmos. É preciso, portanto, que se tenha clareza desses níveis, sabendo que isso se dá em forma de processo evolutivo. Contudo, os homens, isto é, a sociedade, podem avançar e regredir, não há um processo contínuo, sem interrupções, de forma progressiva, pois o saber da cultura ou metafísico caiu em esquecimento, ao menos na valoração, e precisa, portanto, ser buscado e implementado mediante o surgimento de líderes, de modelos que representem esse saber. Segundo Scheler, é preciso recuperar a dimensão do saber que caiu em esquecimento, principalmente, por meio de duas vias: desestruturação e mudança de atitude.

O processo da recuperação do saber que caiu em esquecimento, o saber do espírito e religioso, implica em enfrentar a superação do ressentimento que caracteriza a sociedade moderna, por priorizar o saber utilitarista, conforme demonstrado em Da viravolta dos valores (SCHELER, 2012).

\section{Fundamentos básicos da visão de educação em Scheler}

Tratar dos fundamentos básicos da visão educacional de humanização de Scheler não deixa de ser um desafio, pois não há, propriamente, uma sistematização da sua visão sobre essa discussão, como fez o autor em relação aos valores. Sendo assim, é preciso extrair seus fundamentos de diferentes textos, sujeitando-se a possíveis equívocos. Desse modo, a tentativa é apresentar o que, até o momento, compreende-se sobre o pensamento educacional de Scheler, ou seja, a filosofia de educação do autor. É preciso, para tanto, considerar sua visão de mundo, sua concepção de valores e sua visão antropológica. É necessário, ainda, ater-se à questão em relação aos seus focos e às fases diferentes do seu pensamento, se houve mudança ou se houve apenas priorização e aprofundamento de certas questões, em especial sobre antropologia filosófica, no decorrer do tempo.

No contexto em que Scheler viveu, em geral, considera-se que seu pensamento pode ser demarcado em dois ou três tempos mais específicos. Segundo Morão (2008, p. 8), a vida e a produção intelectual do autor podem ser divididas em dois períodos: o primeiro, entre os anos de 1897 e 1920, quando suas preocupações centravam-se na emoção humana do amor, da natureza da pessoa, em especial nos valores e em sua hierarquia, etc.; o segundo, entre os anos de 1920 e 1928, época em que passa a se distanciar da fé cristã, voltando-se mais para a antropologia filosófica sobre a energia vital, cósmica, etc.

Schaefer (1995) considera que existem três interpretações diferente das fases de Scheler: a primeira interpretação afirma que há uma unidade de pensamento e continuidade; a segunda, que há uma ruptura em seu pensamento, verificada por 
volta de 1922; a terceira admite três fases, a primeira, até 1894, período de Iena; a segunda, até 1922, considerado o "período clássico"; e, posteriormente, até a sua morte, a "última filosofia", com foco na antropologia filosófica. O que parece ter permanecido no decorrer da sua análise e reflexão é a centralidade no homem, em que se pode perceber uma mudança do foco mais religioso para o antropológico e os valores cuja concepção básica não mudou (ética), isso se tomarmos como base seu texto Do eterno no homem (2015), de 1916, e compararmos com A posição do homem no cosmos (2003), de 1928.

\section{Conceito sobre os valores}

Sabe-se que os valores foram um objeto central das preocupações filosóficas de Scheler, principalmente na chamada primeira fase de produção teórica do autor. Inicialmente, em razão de discordância com Kant no campo da ética, Scheler procurou mostrar os erros e aprestar uma alternativa entre o relativismo e o absolutismo kantiano. Em torno desse objeto, vários trabalhos foram realizados em forma de teses, dissertações ou artigos. Dentre alguns, como exemplo, destacam-se: de José Silveira da Costa (1996), a obra Max Scheler - o personalismo ético; a dissertação publicada em livro de Rosane Pereira (2000), intitulada $O$ sistema ético-filosófico dos valores de Max Scheler; e A crise dos valores éticos segundo Max Scheler, de Emerson Ginetti (2010). No texto clássico de Scheler, conhecido pelo título Der Formalismus in der Ethik und die materiale Wertethik, de 1916, encontram-se elementos fundantes da educação, sobretudo o conceito de valores.

Scheler elaborou um sistema axiológico que se enquadra entre os que concebem os valores como sendo objetivos. Harmann é exemplo disso. Esse enquadramento apresenta, no entanto, diferenciação. Enquanto Harmann foca a hierarquia dos valores com base em sua força, Scheler concebe a hierarquia com base na importância. Em síntese, para ele, os valores são objetivos, existe a priori a experiência de forma hierárquica, do menos importante e imediato ao mais importante e mediato, dos materiais aos vitais, éticos e religiosos. Os homens não os criam, intuem-nos e valoram. Sendo assim, os valores éticos e religiosos são absolutos, e a relatividade deles decorre da forma ou do nível de valoração.

Para Scheler, os valores são condicionantes, os homens decidem e agem por meio da sua valoração e, nesse sentido, tornam-se fundamento para a educação. As ações educativas e os projetos educacionais baseiam-se nos valores de acordo com sua valoração hierárquica. Também as espécies ou formas do saber, conforme indicado, relacionam-se com a hierarquia dos valores. Por isso a crítica do autor ao mero tecnicismo, utilitarismo ou pragmatismo, que representa a espécie e a forma 
do saber de domínio relacionada aos valores mais baixos. É preciso que a educação, como destinação do homem, resgate e tome como base os valores, em especial, os mais altos, éticos e espirituais.

Ringer (2000, p. 315) lembra que, na virada do século XIX para o século XX, a tendência de comparar os métodos educativos ingleses com os alemães trouxe preocupações com os valores, houve um combate à tendência que tratava os valores e as ideias como puramente históricos. O autor lembra, também, que, “[...] na concepção de Rickert, os valores eram os principais fundamentos desse universo, sua filosofia da cultura parecia prometer a descoberta de verdades morais permanentes" (RINGER, 2000, p. 310). Com isso, queremos dizer que a questão dos valores era objeto de consideração não só de Scheler, mas também de outros naquele contexto.

\section{Conceito sobre o homem}

Considerar o conceito de homem e sua visão antropológica como um dos fundamentos da educação não pode ser visto em separado dos valores, até porque os valores se manifestam por meio de suportes, e, nesse sentido, o ser humano é um suporte de excelência do valor mais alto: o amor. Essa separação é feita muito mais por uma questão didática e não de realidade.

Schaefer (1995) defende, em sua dissertação, que a base da educação é a antropologia. O pesquisador tomou por referencial, em especial, o último texto de Scheler, A posição do homem no cosmos, que considera ser a síntese da visão dele sobre o homem. Scheler deixa claro que a grande questão é: que é o homem? Sem a pretensão de desenvolver sua visão antropológica, é preciso reconhecer que, a partir de 1922, alguns estudiosos consideram haver uma mudança de foco nos estudos de Scheler, até porque a própria realidade assim o desafiava. Ele, então, volta-se a questões do homem e acaba tecendo críticas ao seu tempo e elencando expectativas da educação daquele homem. Scheler, no prefácio da primeira edição de sua obra, afirma: "Desde o primeiro despertar da minha consciência filosófica, as perguntas: o que é o homem? e qual é a sua posição no interior do ser? me ocuparam mais essencialmente do que qualquer outra pergunta filosófica" (2003, p. 1). O filósofo define o homem como um ser que pode ser compreendido como pulsão e espírito:

O homem é, por si, um ser superior e sublime, acima de toda a vida e seus valores, acima da totalidade da natureza; o ser em quem a psique se purificou e se libertou do serviço que presta à vida elevando-se ao espírito, a um espírito a cujo serviço se coloca agora a vida tanto no sentido objetivo quanto no subjetivo-psíquico (SCHELER, 1986, p. 37).

Scheler rejeitou a visão antropológica dos que entendiam que o homem se diferenciava dos outros seres vivos, particularmente dos animais, pela inteligência, 
como se a inteligência fosse monopólio exclusivo do homem ou dos que negavam qualquer diferença de forma essencial entre o homem e os animais (SCHAEFER, 1995). Segundo ele, há, sim, uma diferença essencial entre os seres vivos, mas essa diferença não ocorre pela inteligência prática, é apenas uma diferença de grau, a diferença radical é pelo espírito e não pela razão. Conforme lembra Schaefer: "Esta diferença essencial depende de um princípio co-constitutivo essencial do homem e faz com que este seja um homem" (1995, p. 99), que é o princípio do espírito, que é a abertura ao mundo, é "seu desprendimento da existencial do orgânico, sua liberdade, sua separabilidade" (SCHELER, 2003, p. 36). O princípio da pulsão representa a tendência para a reprodução, a produção econômica e a dominação, que se identifica com a espécie do saber da dominação ou realização, com os valores mais baixos, enquanto o espírito é o saber das essências e o princípio prioritário da educação.

A visão de educação de Scheler tem como base esse conceito de homem, cuja formação do seu vir a ser como microcosmo não pode ser limitada ao racional, antes, tem como a priori o amor.

\section{Conceito de educação como humanização}

A partir de dois fundamentos básicos - valores e conceito de homem -, podemos tentar uma conceituação de educação. Scheler mesmo diz que educação é humanização. É verdade que temos que considerar que sua formação tem uma herança humanista e que o embate e o debate, em sua época, davam-se em torno de uma educação, de um lado, de caráter humanista e, de outro, com ênfase prática, técnica e utilitarista. Há algumas categorias que estavam presentes nos discursos dos acadêmicos da sua época: Bildung, cultura e espírito.

Scheler deixa claro que não desvalorizava, como os radicais acadêmicos alemães, uma formação mais popular ou, ao menos, o acesso da população das classes mais baixas a uma formação do espírito. As palavras Bildung, cultura e espírito, muitas vezes, foram usadas como sinônimas. No entanto, a palavra Bildung está mais restrita ao que se pode entender sobre ela. Sobre isso, Schaefer esclarece: "A Bildung é destinação, a saber, destinação individual, singular, tanto das nações, das entidades culturais, quanto, finalmente, de cada homem em particular" (1995, p. 53). Scheler afirma:

Wer selbst sich bilden will oder anderen, soweit dies möglich ist von auzen, Bildung geben will, der dedarf siner klaren Einsicht in drei Problemkreise: was ist denn überhauat das Wessen der Bildung? Eie wird den Bilfung? Und was für Artewn und Formen des Wissens und Erkennens bedingen und bestimmen des Prozez, durch des aus dem Menchen ein gebjildetes Wesen wird? (1947, p. 5). ${ }^{1}$ 
Assim, podemos considerar que Bildung é mais o processo educacional enquanto cultura, modo de ser. Quando é usado o termo cultura, pode-se compreender como um "cultivo da alma", que "corresponde ao modo específico de ser" (SCHELER 1986, p. 22). Segundo as palavras de Scheler:

A cultura é portanto uma categoria do ser, não do saber e da experiência. A cultura é a moldagem, a formação deste total ser humano; mas a moldagem e formão não de uma substância material, como no caso da forma de uma estátua ou de um quadro, mas de uma totalidade viva, na forma do tempo, de uma totalidade que não consiste em outra coisa a não ser em evoluções, processos, atos (1986, p. 22).

\section{Ainda sobre cultura, Scheler comenta:}

A cultura não é aprendizagem para algo, para uma profissão, uma especialidade, uma realização qualquer; nem a cultura existe em vista de uma tal aprendizagem. Mas toda a aprendizagem para algo existe em vista da cultura que carece qualquer objetivo externo, em vista do próprio homem na sua forma perfeita (1986, p. 39).

Educação como humanização requer que ela seja voltada à formação do saber das essências e do espírito, ou seja, para a deificação.

Não é, como se pensava, a inteligência prática e técnica do homem que o torna homem no sentido essencial; nele ela aumentou enormemente apenas no sentido quantitativo, alcançando o grau de um Siemens ou um Edison. O que constitui o elemento novo no homem é a realização de atos sujeitos a leis autônomas, independentes de toda causalidade vital psíquica (inclusive a inteligência prática, guiada por impulsos) - leis que não são mais análogas e paralelas aos processos funcionais do sistema nervoso, mas à estrutura objetiva das coisas e dos valores do próprio mundo (SCHELER, 1986, p. 35).

\section{Processo/projeto educativo - reconstrução cultural e conciliação}

Outro aspecto que pode ser apreendido dos seus textos sobre a educação, mesmo não tratando especificamente da questão metodológica, é que Scheler vê que a educação pode ser compreendida como projeto e processo. É importante destacar que, em sua visão, a educação ocupa um lugar central quando pensa sobre acontecimentos históricos e mudanças esperadas e buscadas. Em uma de suas conferências na Urânia, em Viena, em 1917, sobre reconstrução cultural da Europa pós-guerra, em que se discutiu a questão do ódio dos alemães bem como do ódio pelos alemães, Scheler (2015) aponta o lugar da educação no processo de reconstrução, um dos caminhos necessários principalmente para a unidade cultural. Em sua análise da situação decadente, vale-se do projeto educacional humanista humboldtiano, o qual, ao mesmo tempo, critica (SCHELER, 2015, p. 576). Entre outras observações, aponta o que precisa ser conservado da cultura da Antiguidade e o que precisa ser inovado, como a visão em relação ao que chama de solidariedade: 
Em terceiro lugar, esse ideal de educação coloca de uma maneira tão unilateral no primeiro plano a formação interior da personalidade, em face da realização específica e da ação em um todo comunitário maximamente desenvolvido que não se torna mais possível transpô-lo para a nossa época (SCHELER, 2015, p. 581).

Quando discute o perfil da formação da juventude pretendido pela educação, considera que:

O ideal cultural da juventude colocará uma vez mais antes de tudo o homem, e, no homem, a pessoa espiritual e individual em sua articulação com a comunidade no dentro de todo o mundo - no lugar das meras coisas, das meras disciplinas, das meras mercadorias, dos meros negócios ou de um mero monstro absoluto, tal como um Estado que porta supostamente apenas em si mesmo a sua salvação (SCHELER, 2015, p. 609).

Em outra de suas palestras, realizada na Escola Superior Alemã de Política, Scheler discursou sobre a questão da conciliação à luz de sua antropologia filosófica. Nesse processo, também destacou o lugar da educação, dizendo que ela, no entanto, não deve ser dicotômica, no caso, prática de um lado e teoria de outro. Num processo de conciliação, não basta uma elite culta, motor da história, é preciso que a população também receba formação culta, humanista, para que se dê a conciliação.

O homem tem que aprender novamente a compreender a grande e invisível solidariedade de todos os seres vivos entre si na vida total, a solidariedade de todos os espíritos no espírito eterno e, ao mesmo tempo, a solidariedade do processo do mundo com o destino da evolução do seu fundamento superior e a solidariedade deste fundamento com o processo do mundo [...] (SCHELER, 1986, p. 120).

Nesse processo, vê-se uma relação entre os três saberes: da "realização", das "essências" e da "metafísica", que são constituídos de forma hierárquica ascendente em importância segundo a hierarquia dos valores.

Nesse sentido, tendo em vista a conciliação, a política educacional deve ser conduzida com base nos três saberes, unindo teoria e prática, conforme pontua:

Em primeiro lugar, a tarefa cultural das nossas escolas alemãs (especialmente das escolas superiores) não pode ser considerada, como foi até agora, algo de ordem secundária, algo casual ao lado da educação tecnológica. A recente conciliação entre trabalho físico e o intelectual (Rathenau), o generoso movimento de educação popular que inspira a alma do proletariado que havia sido quase fatalmente excluído dos valores espirituais da nação, só é possível se também as camadas mais altas da sociedade compreenderem a tarefa cultural como rigorosamente independente. Mero saber técnico e método técnico dividem os homens; um genuíno saber cultural, entretanto, pode permitir-lhes respirar juntos num espaço espiritual nacional. Uma minoria de técnicos não educados, impostos a uma massa não formada de operários, seria uma barbárie civilizada! (SCHELER, 1986, p. 122). 
A educação é um processo/projeto, pois o ser humano é um tornar-se homem, aspira à Bildung, sendo, com isso, um devir sem descanso. Esse processo não ocorre numa evolução biológica, mas de humanização, de deificação. Sua diferença, como já dito anteriormente, não é de grau em relação aos demais seres da natureza, há uma diferença essencial: o homem é cidadão de dois mundos, ser natural e ser espiritual, pulsão (Rhang) e espírito (Geist). Pulsão é tendência à reprodução, produção econômica e dominação. O espírito é abertura ao mundo das essências, livre da sujeição ao instinto, por isso, eleva-se ao reino do ser e do valor. Desse modo, a educação não está em vista de alguma coisa, de especialização, de aptidão para o domínio técnico, mas para a humanização.

A condição primeira, na visão da educação como destinação, é que ela é individual, singular e ocorre no decurso de uma vida vivida em contato e em ligação com o mundo, no amor e na ação, com engajamento na gratitude. $\mathrm{O}$ agente principal nesse processo é o homem individual, situado com o outro no mundo. A educação é um fazer-se a partir de si mesmo.

No processo educativo, que não se dá exclusivamente por meio da educação escolar, ocorrem numerosas influências exteriores. Todavia, o agente principal: o ser que se educa, destinado a ser, é um ser relacional, que, contrário ao individualismo liberal, inclui o princípio da solidariedade. Entre uma multiplicidade de estimulantes externos, tais como hereditariedade, meio, classe, grupo, época, que podem ser negativos ou positivos no processo da formação, Scheler dá um lugar importante ao indivíduo como pessoa, aponta a imitação de um modelo externo a ser seguido. $\mathrm{O}$ modelo externo não é simples objeto de imitação, sua função é ser revelador, guia, capaz de levar a entender o apelo de nossa própria pessoa à destinação para humanização. Sua tarefa é de despertar, de libertar, e não de se submeter ao modelo. Segundo Scheler, ao discutir, torna-se pessoa, e como lembra Pereira, "[...] enquanto ele quiser o que querem seus pais, seus educadores ou quaisquer membros de seu ambiente, sem estar ainda em condições de reconhecer, no querer de um conteúdo, a vontade de um outro, quer dizer de uma pessoa diferente dele mesmo" (2000, p. 141), considera-se que ainda não atingiu a maior idade, pois um menor ainda não consegue distinguir seu querer de outrem. Para Kant, a maior idade ou a autonomia é predicado da razão, já para Scheler, é predicado da pessoa enquanto pessoa, distinguindo dois tipos de autonomia: "[...] a autonomia do discernimento pessoal, que se opõem a heteronomia do querer sem discernimento, ou o querer cego" e "[...] a autonomia do querer pessoal, esta opõe-se a heteronomia do querer forçado" (PEREIRA, 2000, p. 144).

O professor tem a função de despertar valores e, ao mesmo tempo, de ser o chefe que tem consciência de sua função. Os próprios alunos sabem do papel do 
professor. É importante que, pelo amor que o vincula aos valores mais elevados, o professor desperte, pelo exemplo, o amor dos seus alunos aos valores mais altos. Scheler diz:

Nós queremos ter nossas universidades ocupadas com pessoas, com mestres espiritualmente exemplares, não com cabeças de ciclope de um olho só que não servem senão à sua disciplina e que não fazem outra coisa além de administrar disciplinas [...] (2015, p. 610).

\section{Considerações finais}

A modernidade foi marcada pelo surgimento de várias teorias educacionais, principalmente voltadas ao ensino e à aprendizagem, tendo suas raízes na visão educacional a partir da reforma protestante, da educação para todos e da prática (LUTERO, 1995, p. 303-325), posteriormente, influenciadas pela psicologia de caráter cognitivista, naturalista/empirista ou materialistas, que já no seu tempo de nascedouro tinham opositores, mas que conseguiram, no decorrer do tempo, ganhar espaço, principalmente no campo da pedagogia. No campo da filosofia educacional, no entanto, há um maior "garimpar" em busca de referenciais antigos e clássicos a partir de filósofos e educadores.

Mesmo que Scheler não seja conhecido como filósofo da educação e nem da Antiguidade, consideramos pertinente trazer algumas de suas concepções relacionadas à educação para discussão e como referencial capaz de contribuir para a análise do atual contexto educacional. Principalmente considerando a tendência de um esvaziamento do saber das humanidades nos currículos da política nacional, em que a primazia é voltada à formação tecnológica e profissional com vistas à produtividade e ao mercado, também objeto de debate em seu tempo, com posicionamento oposto a isso, sobretudo na ocasião da reforma educacional na Alemanha. Mesmo quando ele fala da educação, não está falando exclusivamente da escolar, mas a tem como preocupação em razão da questão fundamental: quem é o homem? Por isso, apreendemos que educação, para ele, é essencialmente humanização.

\section{Nota}

1 Tradução: "Aquele que quer cultivar a si mesmo ou ao outro, na medida em que for possível fazê-lo de fora, precisa possuir uma compreensão clara de três espécies de problemas. Primeiro: qual é, em geral, a essência da cultura? Segundo: como se produz a cultura? E terceiro: que espécie e formas do saber e do conhecimento condicionam e determinam o processo pelo qual o homem se torna um ser culto?" (SCHELER, 1986, p. 24). 


\section{Referências}

COSTA, José Silveira da. Max Scheler - o personalismo ético. São Paulo: Moderna, 1996.

GINETTI, Emerson. A crise dos valores éticos segundo Max Scheler. 2010. Dissertação (Mestrado em Filosofia)-Faculdade de Filosofia, Letras e Ciências Humanas, Pontifícia Universidade Católica de São Paulo, São Paulo, 2010.

LUTERO, Martinho. Obras selecionadas. São Leopoldo: Sinodal; Porto Alegre: Concórdia, 1995. v. 5. p. 303-325.

MEISTER, José Antônio Fracalossi. Amor X conhecimento: inter-relação ético-conceitual em Max Scheler. Porto Alegre: EDIPUCRS, 1994.

MORÃO, Artur. A situação do homem no cosmos. Lisboa: Texto \& Grafias, 2008.

PEREIRA, Rosane Maria Batista. O sistema ético-filosófico dos valores de Max Scheler. Porto Alegre: EST Edições, 2000.

RINGER, Fritz K. O declínio dos mandarins alemães. São Paulo: Edusp, 2000.

SCHAEFER, Osmar Miguel. Antropologia filosófica e educação: perspectivas a partir de Max Scheler. Pelotas: Educat, 1995.

SCHELER, Max. Der Formalismos in der Ethic und die materiale Wertethik. Berna: s/ed, 1960. . Visão filosófica do mundo. São Paulo: Perspectiva, 1986.

. Da viravolta dos valores. Petrópolis: Vozes, 2012.

. A posição do homem no cosmos. Rio de Janeiro: Forense Universitária, 2003.

. Modelos \& líderes. Trad. Ireneu Martim. Curitiba: Champagnat, 1998.

. Do eterno no homem. Trad. Marco Antonio Casanova. Petrópolis: Vozes; Bragança Paulista: Editora Universitária São Francisco, 2015.

. Bildung und Wissen. Franfurt: G. Schulte - Bulmke, 1947.

. Universidad y universidad popular. 5. ed. Buenos Aires: Editorial Sudamericana, 1959. . Bildung um Wissens. Franfurt: Bulmke, 1947. 